WEDNESDAY, MARCH 30TH, 1898.

The Twenty-fourth Annual General Meeting of the Society was held in the Linnean Hall, Ithaca Road, Elizabeth Bay, on Wednesday evening, March 30th, 1898.

Professor J. T. Wilson, M.B., Ch.M., President, in the Chair.

The Minutes of the previous Annual General Meeting were read and confirmed.

The President then delivered the Annual Address.

\title{
PRESIDENTIAL ADDRESS.
}

In reviewing the work of the past Session, it is satisfactory to be able to report that it has been a decidedly busy one. The full number of Meetings was held, the number of papers read being forty-nine. The majority of these are contained in the three Parts of the Proceedings for 1897 which have been published and distributed. The balance of the papers are already in type, so that the concluding Part is well advanced.

Nine Ordinary Members were elected into the Society during the year; one Member resigned on his departure from Australia; and the Roll has been further depleted by the demise of one Ordinary and one Corresponding Member.

Mr Robert Cooper Walker, late Principal Librarian of the Sydney Public Library, who died on July 25th, 1897, in his 65th year, was one of the Society's Original Members who kept up his membership to the last. He was the son of the late Rev. James Walker, M.A., Oxon., some time Head Master of the King's School, Parramatta. Mr. Walker was born in England, but came to the Colony while still young. He entered the public service in 1855; and in 1869 he was appointed to the position of 
Principal Librarian of the Public Library, which he held until his retirement on a pension in 1893. The Public Library developed very considerably during Mr. Walker's lengthy administration. One branch of it especially commanded his attention, namely, the literature relating to Australasia. As a result, and with the co-operation of the Trustees, the Sydney Public Library now possesses a very fine collection of publications and documents of this character; and in 1893, under Mr. Walker's editorship, a bulky quarto bibliography relating to the same was published. Mr. Walker was not directly interested in the special pursuits which it is the primary object of this Society to foster. His membership, as in the case of many of the Original Members, was to some extent rather the expression of his sympathetic recognition of the claims of a Scientific Society for support on the broad general grounds of education and culture.

No doubt the Society was most in need of support in the critical period of its very early history. The number of those in a position to contribute papers, and the amount of work done, have since then been steadily on the increase. But, taking into account the general increase in the population and the considerable development of the Colony since 1875, the Council cannot but regret that there has been a falling off in the membership, especially in that section of it of which Mr. Walker was a representative.

Professor Thomas Jeffery Parker, D.Sc., F.R.S., who died on November 7th, 1897, at the early age of 47, was elected a Corresponding Member in 1893. He was the eldest son of the late William Kitchen Parker, F.R.S., the well-known comparative osteologist and morphologist, and was alike eminent as teacher and as investigator. Until his appointment to Otago in 1880, Professor Parker for a number of years was Professor Huxley's Demonstrator at the School of Mines, and there he materially assisted his distinguished colleague in developing the biological portion of the curriculum along the lines which made it as a biological course second to none in the United Kingdom. In "Nature" of January 6th, 1898, will be found a most interest- 
ing and appreciative sketch of Jeffery Parker's life and work, written by his old friend, colleague and successor, Professor G. B. Howes, F.R.S. It is so difficult for one possessed of less personal knowledge to speak effectively on a subject of this kind after a deliverance by one who has spoken with full personal knowledge, that it were wise not to attempt to supplement what Professor Howes has so admirably and so sympathetically given us. I may content myself, therefore, with commending to your perusal the article to which I have referred.

It is fitting, also, that some reference should be made to two other well-known members of the community who passed away in July last, within a few days of each other and of Mr. Walker. Sir Patrick Jennings, K.C.M.G., who died on July 11th, aged 66 years, was an Original Member of the Society who maintained his membership until quite recently. He was well known by his lengthy political career, by his association with the cause of higher education as a member of the Senate of the University, and by his great interest in art and music, and in public affairs generally.

The Venerable Archdeacon R. L. King, B.A., Cantab., who died on July 24th, 1897, aged 74, though never a Member of this Society, actively co-operated with Sir William Macleay in carrying on the work of the Entomological Society of New South Wales, to which he contributed a number of papers, and of which for two years he was President. Mr. King was the eldest son of the late Admiral King, so well known in the annals of Australian maritime exploration. During his residence in Parramatta as Incumbent of St. John's Church, and for some little time after his removal to Liverpool as Principal of the Moore Theological College, Mr. King took up the study of natural history as a hobby, and for a busy man he succeeded in accomplishing a surprising amount of entomological and other zoological work, until the pressure of official duties and want of leisure obliged him to give it up altogether. With the exception of several papers on Entomostraca contributed to the Royal Society of Tasmania, and published in the Papers and Proceedings 
for 1852-54, all Mr. King's papers will be found in the two volumes of Transactions of the Entomological Society of N. S. Wales.

In December last our respected Hon. Treasurer, the Hon. Dr. Norton, communicated to the Council his wish to be relieved of the responsibilities of office, finding it desirable in the interests of health to forego some of the official duties with which in his leisure he has long voluntarily occupied himself. In accepting Dr. Norton's resignation, the Council unanimously resolved that there should be entered on the official records a minute expressive of the Council's regret at his retirement, and of its appreciation of the valuable services which Dr. Norton had cheerfully rendered to the Society without intermission since January, 1882.

Under the new rules now in force, the appointment of the Hon Treasurer rests with the Council. I am glad to be able to report that, on the nomination of his predecessor, Mr. P. N. Trebeck, whose business qualifications are of a high order, was elected to and has kindly consented to fill the vacancy which under the gradual unfolding of the plans of the founder of the Society is not now the sinecure it used to be when the Society's finances were on a more humble scale.

An important achievement of last Session was the revision and extension of the Society's Rules. The Council had learnt by experience that some such step in this direction was to be desired. Early in the year a Committee was appointed to consider and report on the whole question. The efforts of the Committee-and in this connection special mention must be made of the valuable assistance rendered by Mr. J. R. Garland-resulted in a draft which was submitted to the Council, and after full consideration and with a few amendments adopted. It was subsequently submitted at a Special General Meeting of the Members in November last, and finally passed without further amendment. Copies of these amended Rules, which are now in force, were issued to Members with the Part of the Proceedings last distributed.

Another important matter which has been settled is the appointment of the first Macleay Bacteriologist. Towards the 
close of the year the Council again took the matter in hand. Applications for the position were invited by advertisement in Britain and in the Colonies. In response nine candidates offered themselves. The applications were referred to the advisory subcommittee to which matters relating to this appointment have throughout been referred, and a selection of two candidates was made. One of these gentlemen was finally appointed by the Council at a Special Meeting on the 4th inst. The successful candidate is Mr. R. Greig Smith, B.Sc Edin., M.Sc. Durh., F.C.S., who has for some time filled the position of Lecturer in Agricultural Chemistry at the Durham College of Science, Newcastleupon-Tyne. Mr. Smith comes to us highly recommended from home, and he has had some continental experience in the laboratories of Prof. Stutzer, of Bonn, and of Herr Alfred Jörgensen, of Copenhagen, as well as the opportunity of acquiring some knowledge of the manufacture of tuberculin as carried out on a large scale in the laboratory of Professor Bang, of Copenhagen.

Whether the candidate finally selected should be a Bacteriologist with a pathological bias, or one with a physiologicochemical, a purely biological, or an industrial bias, were questions which obviously could hardly escape notice and consideration. As matters turned out these questions were settled by circumstances rather than by the direct intervention of the Council. The essential thing is that the Macleay Bacteriologist should be engaged in doing good work. The encyclopædic Presidential Address of Prof. Marshall Ward in the Botanical Section at the recent Meeting of the British Association for the Advancement of Science in Toronto makes it abundantly evident that, over and above purely pathological developments, the operations of bacteria in a thousand ways affect us in matters relating to our daily life, our homes, our food and drink, our domestic animals and our industries. So that here, not less than in the field of infectious diseases, there is ample scope for the investigations of the Bacteriologist who is working only with scientific ends in view. 
In this connection, though not a matter directly concerning this Society, it is a matter for congratulation to note the recent appointment of Dr. F. Tidswell, lately Demonstrator in Physiology in the University of Sydney in succession to Dr. Martin, as Bacteriologist to, and the establishment of a Biological and Bacteriological Laboratory in connection with, the Board of Health. This important new departure, taken in conjunction with the appointment of the Macleay Bacteriologist, betokens a noteworthy improvement in the prospects of scientific Bacteriology in this colony.

Passing now from the consideration of the Society's more private concerns, I propose to touch upon one or two outside matters of interest. In October last some of us had the pleasure of boarding the s.s. John Williams to welcome back Professor and Mrs. David and some of the members of the party which visited the island of Funafuti last year for the purpose of putting down a bore in the coral reef. At the time of Professor David's departure from the island, the boring had reached a depth of 557 feet without getting through the reef. Later on Mr. Sweet arrived with the rest of the party, bringing the news that a depth of 698 feet had been finally reached, but without touching bedrock. We have had the pleasure of hearing from Professor David a general account of his visit; and in a recent number of the Proceedings of the Royal Society of London (Vol. lxii. p. 200, Dec. 1897), will be found his Preliminary Report on the results of the expedition; so that I need not enter into further details. But I cannot allow this occasion to pass without doing what, I feel sure the Society will look to me to do, namely, to tender to Professor David and his coadjutors not only the hearty congratulations of this Society on the success which has attended their enthusiastic labours, but also our earnest wishes for complete success in any further efforts which he may be able to make towards settling this important question.

In the early part of January of this year the Australasian Association for the Advancement of Science held its seventh Meeting in this city. As you already know, the Meeting in the 
opinion of those best qualified to judge was by no means the least successful and enjoyable of the series. Representative visitors from the other colonies were strongly in evidence, and the opportunities for comparing notes, for exchanging ideas, for talking over questions of correlation and problems of intercolonial and general interest, and for the promotion of good fellowship generally, were freely taken advantage of. The proceedings of Section D., Biology, were somewhat clouded by the lamented death of Professor Jeffery Parker, D.Sc., F.R.S., President elect. Professor C. J. Martin at short notice kindly agreed to fill the breach, and both by his interesting Address, and by his genial and efficient exercise of the functions of Chairman, contributed in a high degree to the success which attended the meetings and deliberations of the Section. On this occasion, for various reasons, the botanists were more strongly and actively represented than the zoologists. They showed their wisdom, too, in having on hand for discussion knotty and perplexing problems of general interest, such as the Classification of the Eucalypts, which can be dealt with to most advantage at the meetings of the Federal Parliament of Science, for then naturalists from widely separated districts in the different Colonies can unburden themselves of their local knowledge, and so contribute to the consideration of difficult questions on broad and comprehensive lines. Zoologists and botanists alike will perhaps be glad to hear that at the next meeting of the Association in Melbourne Professor Spencer hopes in a similar manner to arrange for some special papers leading up to the discussion of biological problems of other than merely local and colonial interest. In no direction perhaps can Section D accomplish better and more useful work.

I trust I may be pardoned for singling out for special remark certain papers which have during the year been published in England, not only since these have been the work of Members of this Society at present absent from Australia but because their subject matter is to a great extent of a very specially Australian interest. I refer to papers by Dr. Robert Broom on the Morphology of Jacobson's Organ in the Mammalia; by Dr. Elliot 
Smith upon the fornix cerebri and the margin of the cerebral cortex, on the origin of the corpus callosum and other neurological subjects; and finally by Mr. J. P. Hill, whose luminous paper on the placenta of Perameles will, I am convinced, remain as a classic record of a discovery of the highest biological import.

Not only is the subject matter of these papers largely drawn from Australian sources, but in each case the papers now referred to may be regarded as containing further records of investigations some of whose preliminary results were formerly communicated to this Society and are embodied in its Proceedings.

Lastly, but of the very first importance, there is to be noted the welcome addition to our libraries of a new Text-book of Zoology, in 2 vols., the joint work of two Australasian biologists. We deeply deplore the fact that the production of this great work should have constituted the final episode in the splendid lifework of Professor Jeffery Parker, to whom, together with his distinguished collaborateur, Professor Haswell, F.R.S., a predecessor in this chair, we owe this magnificent compendium of Zoological learning. The book is, I believe, unique in plan and conception. Its unsurpassed wealth of illustration reflects credit alike on authors and publishers, and, along with the pre-eminent excellence of its plan of exposition, must commend it to a place as an educational aid and a general work of reference, hitherto unoccupied, so far as I know, by any other treatise.

I am confident that you all join me in heartily congratulating Professor Haswell on the completion of this great undertaking, as well as upon the recognition by the Royal Society of London of his own acknowledged reputation as a scientific investigator, in his election during last year as a Fellow of that august body.

On glancing around for a subject which I might most suitably take as the leading subject of my address this evening, I early realised that the situation was, for me, by no means an easy one. It so happens that the matters which of late have chiefly occupied my attention are for the most part of such specialised character that the interest they possess for the general biologist is necessarily slight. On the other hand, I have to regret that my own 
acquaintance with systematic natural history-the aspect of biology which on the whole most directly concerns my fellowmembers - is a very narrow one. In view of my positive disqualification from this point of view, I cannot help feeling that my acceptance of the honourable office to which you were good enough last year to call me has placed me in a position which, if not wholly false, is at least somewhat misleading.

I am not in a position to review the recent work in any large division of biological science; nor am I prepared with a contribution towards the advancement of knowledge in any important subdivision of biological inquiry.

How, then, can I best attempt to reveal the intellectual sympathy which yet undoubtedly underlies the relation between us as members of this Society - a sympathy which serves to unite persons of such diverse interests as geologists, physiologists, botanists and entomologists in the common bond of a kindred spirit? Need I do more on an occasion like this than ask you to call to mind the name under which as a Society we are enrolled ? For, to the whole civilised world of to-day, the name of the illustrious Swedish Naturalist stands for that of fellowship in that true Nature-worship which consists in lifelong devotion to any one of her manifold aspects, and of which our Society is at once a means and an expression.

The interpretation of the phenomena of life and organisation in some detailed province is what each of us is attempting from day to day, and in his own way, to realise. Yet perhaps it is as well that we should occasionally detach ourselves from the engrossing and fascinating details of our special work, and ask ourselves - not as scientific specialists, but as biologists in a wider sense-what these familiar yet mysterious phenomena of life may imply.

However much the necessities of specialisation may separate us in the everyday aspects of our work, here, at least, we shall be upon common ground. And should such an undertaking require apology, it is that my own qualifications to be the exponent of such topics are so meagre. Yet even this imperfect 
attempt may be of service in anew directing your own thoughts upon subjects which cannot entirely or for long be kept in the background.

In order to bring under our consideration some of the governing ideas of modern, biology, it is well and even necessary to look backwards toward the earlier stages of their growth.

For our present purpose, it is unnecessary to attempt a complete historical retrospect.

From the scientific awakening which characterised the period of the Renaissance up to the early part of the eighteenth century the progress of natural science had been steady and assured.

But when we attempt to realise the state of biological thought in what may be called the Linnean period of the eighteenth century it is necessary to have regard to the conditions imposed upon it by the state of knowledge in other departments, and by the restrictions of a very limited technique of investigation.

It is difficult fully to realise the aspect which the problems of biology presented to men for whom nearly the whole of modern chemistry, and so much of the methods and results of experimental physics, were still non-existent. Microscopy, too, though practised, it is true, as early as the previous century, had made little progress; and though it had been the means of revealing a number of additional structural facts, it cannot be said to have taken rank as a reliable or habitual instrument of research. Of the minute structural characters of living tissue, hardly anything at all was known, whilst the processes and reactions of which these tissues are at once the seat and the essential mechanism were likewise wrapped in the profoundest obscurity. And if these internal relationships of organism were little understood, the interpretation of the external relationship subsisting between organism and organism both in structure and in function was likewise profoundly limited and restricted by the current conceptions of the relations between past and present in the world's history.

The Copernican revolution in astronomy has been rightly regarded as a symbol and an expression of a far more general 53 
change, which affected man's entire attitude towards the problems presented by his own being and by the world around him.

The gradual but momentous change in point of view which thus set in revealed itself in many directions, but preeminently in the impetus given to methods of naturalistic interpretation of phenomena.

Closely associated with this tendency was another which made for an "emancipation of our ideas of the past from their bondage to the present" in the interpretation of sequences of events in time. This we may describe as the dawn of the scientific historical method, whose fuller development and wider application to the most varied phenomena has borne such remarkable fruit during the present century.

It was not, indeed, within the domain of the natural sciences, strictly so-called, that the first indications of the development of this method may be clearly perceived. Rather it took form as applied in explanation of the successive aspects of philosophic thought in the eighteenth century. Yet evolutionary science is its flower or fruit; and if this cannot safely be said to have arisen primarily as a biological speculation, it is nevertheless the greatest achievement of modern biology to have provided a detailed demonstration of some of its leading factors and modes of operation in one great sphere of cosmic phenomena.

A brief consideration of the state of biological opinion in the time of Linnaeus may serve to make the subsequent progress clearer. Linnaeus himself was far from being a highly speculative biologist. Preeminently an observer and recorder of facts, his monumental system of classification was admirably adapted to the necessities of his generation. Although substantially a morphological system, based upon facts of structure, the Linnaean classification was artificial as regards its criteria. Still, for Linnaeus himself, those more or less arbitrary structural criteria were only the earmarks, as it were, of a true and actual relationship of the different plants and animals to each other. Such a relationship was conceived by him as indicative of community of origin in the beginning of things in the creative 
thought of the Maker of the universe. It was not regarded by Linnaeus as an expression of morphological identity of origin by the genuine and natural blood-relationship of descent.

For a considerable period, indeed, Linnaeus maintained the doctrine of the absolute fixity of species. Each species was a final form, a finished product, direct from the hands of the Creator. Yet in later life his views on this question underwent a slight modification. He seems to have held that it was in the genus of to-day that we have to recognise primitive species, and that the differentiation which subsequently ensued was due to hybridisation with other species, thus generating new, but in a sense degenerate, specific forms.

On the whole the views of Linnaeus represent the conservative and non-speculative tendencies of his age. On the other hand, his enormous industry served to accumulate vast stores of those materials which were the essential condition of subsequent progress in scientific hypothesis.

If we wish to gain an insight into the more speculative tendencies of the time of Linnaeus we must turn to his great French contemporary Buffon. The history of the growth and development of the evolution doctrine well illustrates the play of the conflicting tendencies represented by these two distinguished Naturalists. Starting from a similar point of view to that of Linnaeus, Buffon's brilliant imagination enabled him far to transcend the current modes of thought, and in a sense to anticipate several of the future determining ideas of biological science. Not only did he come to doubt the fixity of organic groups, but he anticipated the theory of the action of environment and even dimly the Darwinian doctrine of natural selection itself.

Fertile and suggestive of future advance as his imagination was, Buffon cannot be said to have himself effected any substantial or immediate change in the scientific opinion of his own day. Still the inspiration of his novel and suggestive ideas for some of his successors was a great and lasting one, more particularly and directly upon his younger friend, Lamarck, and also upon Geoffroy St. Hilaire. 
When the infallibility of the dogma of fixity of species had been seriously questioned by men like Linnaeus and Buffon, the first and very momentous step had been taken in the direction of the modern standpoint. From this time forth transformist ideas never lacked adherents, though the issue of the conflict with the conservative doctrine of fixity was, owing largely to the later overwhelming influence of Cuvier, for long to remain doubt. ful. Meanwhile the problem for the transformists became even more complicated. For, supposing it to be granted that structural modification of organic forms has actually occurred, the question then arises: "How, and by what agencies, are we to suppose that this transformation has been effected?" In other words, what are the factors in the hypothetical process of evolution?

In attempting to answer this question the cardinal biological fact of adaptation between organism and its environment stood forth as above demanding recognition and explanation.

How could this harmony or unity be imagined to have been attained and preserved alongside of, and perhaps in spite of, disturbing modifying influences? Two possible answers obviously presented themselves from the naturalistic point of view. Either the direct operation of environment has determined structural change and variation in a passive and plastic organism in the direction of harmony with itself; or, on the other hand, the initiative must in some sense have come from within the organism. The latter must then be conceived as an active agent which, under the pressure of an internal "organic necessity," adapts itself, though in reaction to environment, by actual if slight structural alterations. Further, such acquired changes, the results of constant habitual and useful adaptation to a changed or changing environment, are permanently embodied and handed on to the offspring by inheritance.

The pre-Darwinian evolutionists may be ranked as adherents of the one or other of these explanatory hypotheses. The elder St. Hilaire may represent those who, with Buffon himself, chose the first alternative, whilst the name of Lamarck is now inseparably linked with the second. 
It will be observed that in both of these hypotheses thus presented there is presupposed the principle of continuity or uniformity in Nature, which indeed lies at the root of every application of the historical method of interpretation. The negative attitude assumed by Cuvier, the great founder of palæontology, towards the entire theory of mutability is, of course, to be correlated with his advocacy of periodic extinction of types and of catastrophic geological hypotheses generally.

The uniformitarian principle was most strongly upheld by Lamarck, and, though for a time it was relegated to the background by the great authority of Cuvier, it once more, and finally, reasserted itself convincingly in Lyell's Principles of Geology in 1830. From the triumph of uniformitarianism the reassertion of the somewhat discredited evolutionary principle was almost a necessary consequence. Yet Lyell himself was a professed agnostic as to the natural causes determining the successive appearance of new forms; and none of the immediate evolutionist precursors of Darwin were able to add anything new to the discussion of the probable factors and conditions of the process they were disposed to advocate.

The part played by the Darwinian conception of natural selection in gaining for the evolution doctrine a practically universal acceptance in the thought of this century, is too familiar to allow of my pressing it on your attention at any length.

It provided, for would-be evolutionists, that basis of natural causation in organic transformation, the absence of which from the earlier evolutionary theories explains their inability to rise above the almost purely speculative stage. Thus, if we take such speculative evolutionism in perhaps its most striking literary expression, we may recognise in the pregnant thought of Goethe a strong and confident conviction of a unity of type and of a "shaping principle which works underground in Nature." For him these were patent and operative principles, and proofs of actual community of origin amongst organic forms. Yet his suggestive biological ideas were unable to reach the condition of acknowledged scientific certainty in the absence of such a theory 
of a modus operandi in the way of natural causation as is for us supplied by the selection theory.

That theory is indeed the answer to Kant's demand for a "mechanism of Nature" which should "give us an insight into the generation" of organic forms, and should confirm his supposition that these "have an actual blood-relationship, due to derivation from a common parent." That natural selection has justified its claim to be considered as just such a "mechanism of Nature "-as a determining factor in evolution-few if any will now deny. Whether or not, on the other hand, it is an allsufficient explanation of the appearance of new structural features, and thus of new organic forms, or whether the Lamarckian factor of use-inheritance also plays the part of 'an integral factor in the process, is even now the subject of most energetic controversy. Into the details of that controversy I do not propose to enter. I would only point out that if the latter factor be admitted to equal rights with the former, the problem of the mode of natural operation, or the mechanism, whereby the effects of use are registered and expressed in definite and transmissible structural alteration, still remains unsolved. But after all this question is not quite a fundamental one. Whether on strictly selectionist principles alone, or with the admission also of use-inheritance, the factor of variation is implied and assumed. Whether, as the selectionist holds, variation is indefinite, and occurs indifferently in all possible directions, or whether, with the Lamarckian, we admit that variation is frequently in a definite and determinate direction, there is yet an element in the chain of natural causation which is fully explained on neither supposition.

It is true that emphasis may be laid, as by Mr. Spencer, and as earlier by St. Hilaire, on the determining effect of environment. But it is next to impossible to prove-and certainly it has not been proved - that simply of itself environment can do anything at all. We can never fully eliminate or distinguish what is due to the reaction of the organism to the environing conditions. Organism is never passive. The distinguishing feature of life consists in activity in the way of adaptation, whether we view it 
in its internal relations as process in the individual organism, or in the external relations of organism to its outer environment. And if we take refuge, as in the meantime we may still permissibly follow Darwin in doing, in the idea of a "spontaneous variability" of organism, this is of course to confess that we are still unable to penetrate far enough into the ultimate mechanism, if we conceive it as such, which underlies the admitted process of organic modification.

Professor Weismann, it is true, attempts wholly to eliminate the action of environment in the production of variations, while assigning to it the exclusive privilege of perpetuating the lucky ones by its selective influence. But it will, I think, be found difficult to do justice to the admitted influence of environment upon the ordinary phenomena of the life of organisms and, as even Weismann admits, upon their somatic structural constituents, and yet jealously and rigidly to exclude these operations from any modifying influence whatsoever upon the germinal constituents. And when even this is actually attempted the resulting effort to account by germ structure for the spontaneous production of the infinite variety necessary for a selection theory, introduces yet another complication into the operations of that tremendous. mechanical apparatus of the germplasm, which has been conjured up in explanation of the facts of hereditary transmission. Still the mere fact that complication of this kind is the result constitutes in itself no valid objection to the theory. But, in the last resort, the expedient merely shifts the difficulty of a solution from one sphere to another; and the dexterous compression of the problem so as to enable it to be hidden out of sight in the ultra-microscopical structure of the chromatin of the germ-cell, even if legitimate, can hardly in the meantime be said to make for simplification.

Concerning the details of the argument between Weismann and his critics I shall say nothing. The general verdict amongst biologists in the meantime would appear to be that its results are so far inconclusive. But I may point out that Weismann's contribution to the general theory of evolution may be regarded as 
a strictly logical continuation of that effort to account for the phenomena of life on the lines of physical causation which the introduction of the conception of natural selection seemed to bring within our reach. In other words, its object is, like that of every purely naturalistic theory, to explain away the teleological phenomenon of adaptation which had appeared to the older biologists to be, prima facie, the cardinal characteristic of all organic process. It aims at replacing the idea of purpose or final cause by the purely physical idea of determination by efficient cause as the ordinary and necessary procedure of all scientific interpretation.

This mechanical tendency in the treatment of the relations of the organism to the external world and to other organisms, in space and time, is not its only expression in modern biological thought. On the physiological side also, dealing with life as manifested in the inner relations of the parts and organs of the body to one another, the same spirit has been active.

The vitalistic interpretations and theories which were current earlier in the century have been subjected to a progressive destructive criticism, and it has been claimed that the more insight we get into the true character of living process, the more clearly does it appear that their natural explanation must come to us in terms of physics and chemistry if at all. And there are abundant proofs that the application of physico-chemical ideas and methods to the investigation of vital phenomena is able to carry us further in the direction of an intelligible explanation of living processes than could formerly have been dreamed of.

Whatever may be the final explanation forced upon us of the real nature of the operation of living activity in an animal organism, it is beyond doubt that our acquaintance with the manner of that operation has grown enormously along with the assumption of its essential identity with inorganic process.

Yet in spite of this there have been many indications during the latter part of this century of a reaction away from mechanical and back towards vitalistic interpretation. 
It has been contended that, notwithstanding the seeming ease with which many of the phenomena of life can be translated into the language of physics and chemistry, we find whenever we push the analysis of function far enough, that eventually we are simply brought back again to the original problem with which our analysis started, in the ultimate dependence of all bodily process upon the life of the individual component cells of the organism.

Our progress-and after all it is progress-has consisted in pursuing the secret of living activity somewhat deeper into the recesses of organisation. And just when we seem to have eliminated something of the mystery of living process, we find that we have only succeeded in storming the outworks, and that the citadel of the vitalistic position yet lies securely intrenched behind the defences of the living cell.

In other words, the essential problem of physiology has merely been transferred from the cell complex, which forms the body or the bodily organ, to the more remote individual organism or cell, which for us in the meantime forms the unit alike of structure and function.

Even more than this may be claimed by the advocate of vitalism. For the interactions, correlations and co-ordinations subsisting between the component cells and parts of an organism, as in the case of a developing embryo, have not hitherto shown themselves amenable to a mechanical interpretation.

On the other hand, it may be said that recent experimental work on the mechanical conditions of developmental processes is making satisfactory progress in this very direction. And even if we admit that in no case has the progress of physiological investigation enabled us actually to reduce living process to terms of chemistry and physics, this need not blind us to the wonderful and significant advance which the effort to do so has procured. It is not too much to say that every year further facts of organisation and additional events in life-processes are having assigned to them their physical and chemical conditions, and are thus so 
far being reduced to the position of elements in the cosmos viewed as a mechanically determined material system.

There seems no reasonable ground for believing that the continued application of the same instruments and principles of research, of the same naturalistic conceptions, which has already yielded such magnificent fruit in the proximate interpretation of function and structure, will henceforth become more and more barren. In the struggle after scientific progress what other weapons have we to rely upon? It is significant that, even amongst those who steadfastly deny the sufficiency of chemicophysical interpretations of living process, are to be numbered investigators who have themselves been forward in the application of the most rigidly exact methods of weight, measurement and analysis, in the study of vital phenomena. They have thus done homage to the methods in which the mechanical principle is already in a sense implied, admitting its applicability to certain aspects at least of the phenomena to be investigated.

Is there then any justification for the contention of the "vitalist" of this latest era in physiology? Is there any point at which the principles of physical and experimental inquiry fail in applicability; any aspect of living activity which they are incapable of embodying?

It is claimed, as we have seen, that physiological investigation has not succeeded in eliminating the idea of purpose from the last interpretation of any biological fact of structure and function which has been offered for analysis.

That science will ever enable us to say that at last we have a perfect, self-consistent and complete mechanical explanation of even the simplest fact of living process or tissue seems to me to be in the highest degree improbable.

The brilliant physiological analysis of the mode of working of the bodily organs which is one of the characteristic products of the biological activity of the century has indeed by no means ceased. But though still proceeding in manifold and specialised directions, it is hampered at almost every turn by the difficulties attaching to an explanation of the living activity of the cell unit. 
And if, to-morrow, this obstacle be partly surmounted-as is likely enough - by further discoveries in the way of intracellular mechanisms than the important ones already made, yet we may be very sure that in every forthcoming interpretation the notion of adaptation or purpose will again re-assert itself, though for a time it may be concealed under the disguise of a mere unexplained residuum which refuses to be read into the next current mechanical hypothesis.

Does it not appear to be the doom of Biology to be for ever endeavouring to reduce such an unexplained residuum? It must never despair of its ability to translate the facts into the language of physical causation. Thus only does it fulfil its mission as a branch of Natural Science which is "to distinguish the threads of necessity that bind together the most disparate phenomena" even though in so doing it may seem to be "explaining away all life and unity in the world and putting everywhere mechanism for organism even in the organic itself."

But we are by no means compelled to assume that the method of explanation thus pursued represents the only mode of apprehension of the facts, the only possible interpretation of their meaning. It is indeed vain to look to Science for the recognition of an aspect of living phenomena which it must of its own inner necessity ignore. On the other hand, "there is little ground," said Prof. Burdon Sanderson in 1889, "for the apprehension that exists in the minds of some that the habit of scrutinising the mechanism of life tends to make men regard what can be so learned as the only kind of knowledge. The tendency is now certainly in the other direction. What we have to guard against is the mixing of two methods, and, so far as we are concerned, the intrusion into our subject of philosophical speculation. Let us willingly and with our hearts do homage to 'divine philosophy,' but let that homage be rendered outside the limits of our science."

It is just such an intrusion of the fruits of a distinctively philosophical interpretation of organisms into the domain of strictly scientific speculation that tends to vitiate the modern 
"vitalistic" views. I am willing to admit that the vitalistic recognition of purpose does, in a sense, more justice to the facts of organism than a method which ignores purpose. But I do not think the idea of purpose helps us at all in strictly scientific and experimental procedure, and its attempted scientific application is simply an attempt to "find a gap in that circle of mechanical motions" which alone constitutes the cosmos for experimental science.

In science properly so called, "the phantoms of life, the final causes" which (as Mr. Caird says in this exact connection) "distort the prose of science" must be resolutely put from us, even though, with them, all hope of finality and unity in the ultimate explanation of the world, from the point of view of physical science, completely disappears.

In a genuinely scientific explanation there is never reached a stage at which we can forsake the mechanical method simply because we can no longer recognise, nor easily imagine, the nature of the unknown antecedents of a phenomenon. Vitalistic or teleological interpretation is not a method which comes to our rescue when a physical interpretation fails us. In so far as it is valid at all, it is one which is present with us and which urges itself upon us at every stage, forbidding us ever to mistake a possible mechanical interconnection of the phenomena of life for the real ground in thought of purposive adaptation. This idea indeed intrudes itself upon our apprehension as the special characteristic of the organic world at any and every stage of scientific development, but it is not a product of the scientific imagination. Any apparent force which latter-day vitalistic objections to the mechanistic procedure of science may possess would seem to depend upon the mixing up of two possible modes of explanation. The endeavour is made, by pointing to the incompetence of the mechanical method to explain certain aspects of living process, to make room within the circle of scientific experience itself for a mode of explanation which has neither relevance nor validity in the sphere of experimental science. 
It is doubtless true enough, as the vitalist maintains, that it is insufficient as an explanation of living process merely "to trace energy from the surroundings through the organism and out to the surroundings again. If," he continues, "this is to be taken to be a full account of the process it is inadequate, for it ignores the fact, characteristic of life, that the energy spent by the organism on its surroundings is not dissipated at random on those surroundings, but is so directed as to cause them to give back again to the organism, sooner or later, just as much energy as the organism has previously expended. In other words, the distinguishing feature of vital activity is self-preservation or the conservation of the organism in a state of functional activity."

The criticism is just, and appropriate enough. But from the strictly scientific point of view the fact that there is not an indefinite, but a definite distribution of energy simply suggests a further search for a mechanism to account for this additional fact of distribution along lines which, as a matter of fact, make for self-preservation. It will not do to say that such a mechanism is inconceivable. It was just such a problem with which Science was confronted during the growth of the theory of Evolution. How was the obvious adaptation of evolving organism to environment to be accounted for on the lines of Natural Causation? The answer to this was the theory of Natural Selection.

And just in so far as the Natural Selection theory eliminates the idea of purpose (contained in adaptation between organism and environment) from the notion of Evolution, so far also - and no further-might a possible extension of mechanical hypothesis enable us to dispense with the idea of final cause suggested by the purposive distribution of bodily energy above referred to.

It will not do to harbour the notion that the current of energy, of which the organism is conceived as the physiological channel, can be either interfered with, or even determined in its direction by, purposive conditions. So to represent it is found to involve the vain attempt "to get at an end or final cause without leaving the point of view of efficient causality." And, just as determinism is within its rights in abolishing the abstract self 
"which claims an empirical freedom of will amid the strife of motives," and as it is impossible "to save for this self even the power of directing attention on one motive rather than another," so, whenever the organism is regarded as a vehicle of energy, it is vain to aim at vindicating the idea of final cause by claiming for it any empirical power of determining the distribution of that energy for ends or purposes.

In the same able essay from which I have quoted the reference to purposive distribution of energy, allusion is made to the wellknown phenomena manifested in the regeneration of the amputated limb of a newt. After summarising the process by which the bud of embryonic tissue goes on to re-form all the tissues of the lost limb, bone, muscle, nerve, dc., the writer proceeds :"Every cell performs its appropriate duty until the whole business is accurately finished without fail. Is it conceivable that each of the thousands of separately existing cells concerned in the process should have a mechanism within it which would cause it in spite of all obstacles to take up the position and undergo the modification requisite for the proper performance of its work in the newly developed hand? Or is it conceivable that mechanical pressure of any kind should cause the bud to grow into a perfect hand? The alternative hypothesis is that each cell is determined directly in its action simply by what it has to do in order that the vital activity of the newt may be restored to its normal condition."

Now to my mind it is not only not impossible but it is almost imperative that we should conceive just such mechanical arrangements as are here assumed to be out of the question. Without such presupposed mechanism no conception of detailed sequences of events could be formed and the entire natural process would have to be regarded as physically unintelligible. But some definite chain of physical events in such a case there must be; and each event must have its physical antecedents and conditions which must almost necessarily be embodied in some sort of structural mechanism. What that mechanism is is of course precisely the kind of question which it is the function of Natural 
Science to ask and her chief business to answer. To the question whether in such a case an answer can even be conceived it ought to be sufficient to reply that of recent years it has been the object of Weismann's elaborate theory of the architecture of the germ plasma to furnish just such an answer. Whether the effort is well or ill-directed to that object it is beside the question to enquire. If not that solution then another, not less mechanical, may be forthcoming.

We may therefore pay little heed to those who would bid us cast away the hope that the closer investigation of cell structure and function may enable us to read even these into the convenient if more abstract terms of mechanism. It does not follow that the mechanism itself will be found to be simple. The nucleus of an ovum, so long as we can say little or nothing of its structure, seems an object of no great complexity. But if we are to make any progress at ail on naturalistic lines, the future advance of biological investigation must consist in unravelling the enormous structural complexity with which we are bound to credit it. And as an attempt in this direction even the demand made on the mechanical imagination by Weismann's stupendous germ plasma may be regarded as not greatly excessive. Such an hypothesis as Nägeli's micellar theory too might likewise open up a most fruitful field of discovery.

It appears to me most probable that ere long we shall arrive at ideas with regard to the architecture, not only of the germplasma, but of the cell as a whole on the lines of some such conceptions as are involved in theories like those of Weismann and Nägeli.

Nor need we pay great heed to the warnings we sometimes hear respecting the bounds to further structural investigation imposed by unavoidable optical limitations, as in the construction of lenses.

It may be true that by-and-bye we shall reach such optical limits. But the implied assumption is hardly warranted, that only by optical means and methods can we possibly in future gain an insight into what we now term the ultra-microscopical structure of living tissue. It is surely quite amongst the 
practical possibilities of future science that the arrangement in space of the material particles of protoplasm supposed; for example, by such an hypothesis as Nägeli's, may be sufficiently attested and verified by other than optical means; it might even be by the incidence on appropriate instruments of other than optical radiations. Who can tell what structural facts may not be borne witness to by future instruments of research?

It seems reasonable to believe that no limit can be assigned to the efforts of science to supply an answer to all questions relating to the "how" of phenomena - to the manner of their being and becoming, past and present.

As to their "why," - their object, purpose or final cause, - that is sometimes declared to be a matter of which we are not only ignorant, but of which we cannot even hope ever to know anything at all. And if what I have already said be true, then it follows that upon such questions Science in the narrower sense must be for ever dumb. We must be content to recognise that its operations are conducted entirely on the plane of a mechanical interpretation of phenomena even when its subject matter consists of organised material and living process.

What place, then, can be assigned to the notion of purpose or final cause in a scheme of human knowledge? Is there any sense in which its validity in the interpretation of the world must be acknowledged? Thus stated, the question need no longer excite the suspicion with which any claim on the part of teleology to strictly scientific validity must be viewed.

It cannot be denied that the adaptation of objects and processes to ends or purposes is plainly and unmistakably suggested to the ordinary human intelligence. It is true that this suggestion is not obviously pressed upon us by a consideration of the facts of the inorganic world. But whenever we enter the domain of organism we find, even in the lowliest expression of living activity, that we can no longer ignore the purposive character of that activity. We seem to have entered upon the exploration of a kingdom of ends, wherein all events that occur suggest not merely, or even chiefly, a dependence upon preceding events, but 
a dependence upon events which have not yet occurred. In other words, organisms appear to perform acts in order that more or less definite results may be brought about; and the nature of the living acts is therefore determined not merely by what has gone before, but by what is yet to follow. "It is that which is about to be that guides the growing thing and gives it unity."

It is this adaptation of means to ends which is put in the forefront in all teleological interpretation. And a very little consideration is sufficient to convince one that this notion of the determination of means by ends not merely differs, but is radically distinct from, that of physical determination by antecedent phenomena. It amounts to a complete inversion of the order of physical causation. *

To assume that since the idea of determination by ends involves a point of view essentially distinct from that of efficient causation the notion of end or purpose must therefore be put aside as a mere preliminary illusion of the intelligence-as a fiction which we accustom ourselves to suppose-is simply to beg the question.

The validity of this or that principle of explanation cannot be decided in a rough and ready fashion. It is not a question simply of the relative success of either principle in enabling us to string facts together in a more or less intelligible order. Both principles may assist us in doing so, and may thus claim to be so far regulative of experience.

To decide upon the limits of the validity of each and all of such principles or categories of explanation is the paramount function of a genuine philosophical criticism. It is to this that

* It is idle to fall back upon Hume's supposed metaphysical elimination of the idea of necessary connection, causal or other, in order to get rid of the difficulty raised by this distinction between efficient and final cause. This destructive criticism is quite as effective in destroying the foundations of ordinary scientific reasoning as in getting rid of the teleological conception. And it has been abundantly shown that on such a basis of philosophical scepticism as to the fundamental conceptions, e.g., of cause and of substance, no system of human knowledge can possibly rest. - Cf. Green's Introd. to Hume's Treatise on Human Nature. 
we must look to enable us to determine the relation to the whole of human experience of any one of the principles which appear to be implied in that experience. Before this tribunal the competing claims of teleology and purely physical determinism, as principles explanatory of Nature, must ultimately be brought. And when this is done it will invariably be found that it is impossible to allow the discussion of the fundamental conceptions of knowledge, like those of substance and cause, to proceed merely with reference to the phenomena of Nature conceived objectively.

In every criticism of the nature of knowledge which is not wholly superficial it will be found that there is involved a reference and a relation to the self-conscious subject of knowledge as the indispensable condition of all experience whatsoever.

This is neither the time nor the place to attempt to set forth what I take to be the results of such a criticism of the conditions of knowledge. I can only permit myself to affirm my own conviction that an impartial study of the problem thus suggested will result in a recognition that the conception of the cosmosthe object of human experience - as a mere system of material and mechanical relations in space and time is after all highly abstract and unreal. For certain purposes such a conception may be not only useful but indispensable, just as are the professed abstractions of mathematical science. But the hypothesis which regards the cosmos of experience as reducible to an endless series of phenomena in time and space, connected by a common bond of external necessity, entirely ignores the fundamental relation of all fact whatever to a knowing subject as the essential condition of all experience. No hypothesis which abstracts from this reality can possibly claim to offer a satisfactory interpretation of things. And it will be found whenever full recognition is afforded to the one inalienable condition of experience, that, amongst other ideas, that of final cause or purpose must be reinstated as a valid and necessary principle of explanation in any philosophical interpre tation of the world.

It is a consequence of the acceptance of such a philosophical doctrine that although, even in biology, we must, if we wish to 
make progress on truly scientific lines, continue to bring all the facts of observation and experiment under the dominant idea of mechanism or physical causation, yet we are continually forced to recognise the incompetence of the mechanical principle to satisfy the intellectual demand for a full comprehension of the significance of living process. And this inadequacy becomes the more glaring as the phenomena to be investigated approximate more and more to the character of manifestations of conscious intellectual activity.

The difficulty arising out of the confusion of two points of view, emerges in one of its most impressive and characteristic forms in the efforts to apply the principle of evolution, in its guise as a principle of natural history, to the manifestations of human activity in social institutions and laws of conduct.

It has indeed been one of the triumphs of the historical method to have largely "emancipated our views of the past from their bondage to the ideas of the present" by means of "the conception of the evolution of man by interaction with his environment."

In its more extreme form, however, this idea of human evolution has been interpreted on the lines of organic evolution generally, as a sequence of natural phenomena causally connected by the aid of the principles of variation, heredity and natural selection.

Earlier in this address I have referred to the representation of natural selection operating upon indefinite variation, as a means of explaining organic adaptation as a purely naturalistic process.

Even as applied to the lower stages of organisation, we saw that this reduction could not be regarded as having been actually effected, so long as the residual phenomenon of variation remained unexplained. Evolutional adaptation still remains dependent upon an inherent "spontaneous," or at least an unexplained variability.

And when we come to apply the conception of evolution to the products of conscious human activity, we find ourselves upon still more uncertain ground. 
The late Prof. Huxley, in the last of his memorable and striking utterances, once again proclaims his deeply-rooted faith in the ultimate unity of all "cosmic process," expressing itself in secular evolution. But he found himself, nevertheless, compelled to postulate within this process a kind of countermovement as regards natural selection, when he is considering certain aspects of human evolution.

"The faith that is born of knowledge," Prof. Huxley says, "finds its object in an eternal order, bringing forth ceaseless change through endless time, in endless space; the manifestations of the cosmic energy alternating between phases of potentiality and phases of explication."

The aspect of cosmic activity which the great apostle of evolution singles out for special treatment in the essay to which I allude, is what we may call the human episode in the cosmic process. This episode, you may remember, he sets forth under the metaphor of a garden, cut off from the unreclaimed bush of general cosmic activity, and tended, watered, and otherwise pro. tected from the incursions of wild animals and the hurtful competition of noxious and undesirable plants. He is not concerned with the origination of the garden, for obviously this must be regarded as in some sense due to the operation of the ordinary laws which govern the entire region. The domesticated area must in some natural way have become shut off from the wildwood. But he is specially concerned with the fact that, given such a garden, the denizens of it are now largely protected from the operation of the ordinary natural and competitive conditions prevailing outside its limits. By this he attempts to convey the notion that one aspect of the result of human evolution by natural selection has been the limitation, within the garden of human society, of the operation of those very conditions of struggle and survival to which its genesis is owing. And he accordingly proclaims the "apparent paradox" that "ethical nature while born of cosmic nature is necessarily at war with its parent." 
No scientific writer of modern times has exhibited a greater mastery of apposite and forcible metaphor than Mr. Huxley. But there have been occasions like that I now refer to when the metaphor is so forcible that it appears to carry off its author bodily.

If ethical process is really the legitimate offspring of the cosmic process, then all the features subsequently revealed in the former have surely a full hereditary title to the name and privileges of the parent. And indeed Mr. Huxley was forward to remark that none was more willing than he to admit the ultimate identity of the two kinds of process. And yet he immediately pushes the idea of the war between offspring and parent so as to warrant the conclusion that the processes somehow become essentially distinct.

It is by no means hard to perceive that the source of the so-called paradox is to be found in Mr. Huxley's identification of " cosmic process," in its evolutionary aspect, chiefly if not entirely with the principle of natural selection. And of course when he goes on to recognise that a condition of human progress on the ethical side has been a restriction and limitation of the struggle for existence amounting almost to the suppression of its internecine features, he is constrained to express the difference as a war between parent and child, between the cosmic and the ethical processes. But surely, and I say it with all respect, this is the most utterly obvious fallacy. Either the forms and institutions of ethical activity are a non-natural product, and no genuine daughters of the cosmic process, or else they are as much cosmic in their origin and essential nature as are the satellites of Jupiter. How can they, from Prof. Huxley's point of view, ever cease to be cosmic or even begin to become anything else?

Such is the preliminary difficulty or confusion. Let us see how it works out in other directions. Allusion is made to "bee society" as a somewhat analogous phenomenon to that of human society. "Bee society," we are informed, "is the direct product of an organic necessity impelling every member of it to a course of action which tends to the good of the whole. Each bee has 
its duty and none has any rights." [Has not the queen as much right to her special appointments as any human monarch to the regal accompaniments of his function? At any rate, if we cannot here speak of a " right," as little can we talk of a "duty."] "In the same sense as the garden or the colony is a work of human art, the bee polity is a work of apiarian art brought about by the cosmic process working through the organisation of the hymenopterous type." Again, he says, "I see no reason for doubt that at its origin human society was as much a product of organic necessity as that of the bees." Then he points out that self-assertion in man is a survival of the original " organic necessity" out of which human polity arose, and that certain "organic necessities" operate as checks upon this "self-assertion," as, for example, family affection, sympathy, \&c. "We come to think," he continues, "in the acquired dialect of morals." "An artificial personality, "the man within,' as Adam Smith calls conscience, is built up beside the natural personality. He is the watchman of society, \&c., \&c." He then goes on:- "I have termed this evolution of the feelings out of which the primitive bonds of human society are so largely forged, into the organised and personified sympathy we call conscience, the 'ethical process.'" But since Prof. Huxley has already taught us to regard this as the natural offspring of the cosmic process arising at the stage of organic necessity, whence comes the arbitrary distinction between the one as "natural" and the other as "artificial?" Surely, the identity of origin forbids us to pit the one against the other as of alien growth! The ethical, if recognisable at all, is " cosmic" through and through, and it is vain to talk as if they were each manifestations of distinct principles.

In the treatment of bee polity, the explanation offered is that it is "a product of an organic necessity impelling every member of it to a course of action which tends to the good of the whole."* Yet when a not dissimilar limitation of the struggle for existence amongst the individuals comprising human society has to be

" This is of course pure "cosmic" activity. 
characterised, it is no longer "cosmic," but "ethical," conceived as directly antagonistic to the former.

I have criticised these views at length because I think it is plain that the source of the confusion is that arbitrary identification of organic "cosmic" process with the process of Natural Selection on a basis of struggle with elimination of the unfit. Now, Mr. Huxley's proclamation that this principle does not prevail in an unmodified form in human society; and even that, to a large extent, the progress of human society does not depend upon the struggle for existence, is tantamount to a declaration that Natural Selection is not the sole and only factor in the movement of the cosmic process. For it is strictly inevitable that we should take the latter in the full and only legitimate sense as embracing the entire conditions of the ethical process as fully as it does the necessities, organic or other, which direct and control either bee society or planetary movements.

I am not here concerned to inquire whether or how far human progress as a manifestation of "ethical process" is characterised by such a suppression of the struggle for existence as has been insisted on. Whether there is substituted for it, in the later phases of human evolution, a struggle for the means of enjoyment, as Mr. Huxley held, or a struggle for existence, with survival of the fittest, not of individuals, but of ideals of action, as Mr. Ritchie believes, is also a matter which may be left undiscussed.

But the admission that the mere extension of the Darwinian theory of natural selection is not fitted to account for the evolution of human society and institutions, at least in the later phases of that process, is one which, as coming from Mr. Huxley's maturer thought, cannot be lightly passed over.

The fact is that when we reach the higher planes of "cosmic process," including in this term the "ethical" element with which Mr. Huxley can only be said to juggle, we find, - not indeed a reason to deny the applicability of the methods of explanation which have proved useful in dealing with simpler phenomenabut that these are no longer to be recognised as capable of satis- 
fying the intellectual demand which the situation makes upon our thought. Such satisfaction as they convey is but formal. The thirst for explanation of the really significant aspect of the complex phenomena of human activity remains practically unquenched.

There may be a relative truth in such a statement as that the phenomena of human history and conduct, the manifestations of the human spirit in art and literature, and of such thought-products as pure mathematics or the more concrete sciences, may be viewed as products of physical sequences in the way of redistributions of matter and energy. In a sense, again, we may be entitled to say that the human events thus conceived have been manifested and epitomised in a structurally variable germplasm, perpetuated by natural selection, and unfolded and brought to fuller fruition as episodes in the functional activity of the modified protoplasm of nerve tissue.

I neither doubt the possibility nor deny the desirability for certain purposes of naturalising in this way the facts and processes of conscious human activity.

Every mode of explanation is relative to a certain point of view. Thus, it will be generally admitted that the hypothesis of human society as constructed solely on the basis of the idea of wealth is incompetent fully to explain the concrete phenomena either of individual or of a corporate social and national life. Yet the science of political economy which to a large extent depends on such an hypothesis has nevertheless its own value and function. Or again, I may borrow an illustration from an essay from which I have already quoted, and point out that "no physicist really supposes that he is dealing with anything else than a metaphysical abstraction as distinguished from a real object, in a purely kinematical investigation."

But the utility of such admittedly provisional hypotheses becomes ever the less the more the obvious complexity of the actual fact obtrudes itself upon our mental horizon. In spite of ourselves our point of view becomes altered; and it is no small part of the discipline of the scientific intelligence to avoid the 
confusion of different categories of explanation; to "put himself aside and let Nature speak," Nature, that is to say, which is for him a purely mechanical system.

And it is just such a confusion of thought which on the other hand permits the presentation of scientific and physical formulas as if these exhausted the reality of living or conscious activity or were other than lame and often grotesque travesties of the actual content of the phenomena in question.

I have already tried to show that at the root of the modern doctrine of natural selection (survival of the luckily endowed) there lies the mechanical principle of external necessity in a determining environment. I have indicated my conviction that it is this aspect of it which vitiates its attempt to explain by itself the ethical aspect of human evolution, and which seemed to give point to the self-contradictory notion of a conflict between the cosmic and the ethical principle.

The fact of a continued process of human evolution cannot be withstood. But we may readily follow Mr. Huxley in his assertion that natural selection does not satisfactorily account for the later phases and stages of it. If, then, we are to retain our grasp of the essential identity of all cosmic process, we must be prepared to recognise that if the end is not intelligibly to be conceived as mere mechanism neither can the beginning be so explained.

And what is true in relation to the ethical aspect of cosmic process as revealed in human society, is true also of the organic aspect of that process as revealed in plant and animal life. The mechanical interpretation is only a convenient, a provisional, abore all a working, hypothesis. As a final or philosophical interpretation it is false, because it ignores one, and that the really significant aspect of the facts viewed from the general philosophical point of view.

And, exactly as in the case of the ethical process, it does not help us much that we are able, by the aid of the doctrine of evolution, to trace back the series of living forms to their simplest, most formless, and structureless beginnings. "The continuity of all existence," which is the essence of the evolu- 
tion idea, "may be interpreted," says one writer, "in two very different ways. It may lead us either to radically change our notions of mind and its activities, or to 'radically change our notions of matter.' We may take as the principle of explanation either the beginning or the end of the process of development. We may say of the simple and crass, "There is all that your rich universe really means'; or we may say of the spiritual activities of man, 'This is what your crude beginning really was.' We may explain the complex by the simple or the simple by the complex."

"And one of the most important questions for morality and religion is the question, which of these two methods is valid. If out of crass matter is evolved all animal and spiritual life, does that prove life to be nothing but matter; or does it not rather show that what we, in our ignorance, took to be mere matter was really something much greater? If 'crass matter' contains all this promise and potency, by what right do we still call it 'crass' "?

"It is manifestly impossible to treat the potencies, assumed to lie in a thing that grows, as if they were of no significance; first to assert that such potencies exist, in saying that the object develops; and then, to neglect them, and to regard the effect as constituted only of its simplest elements. Either these potencies are not in the object, or else the object has in it, and is, at the first, more than it appears to be. Either the object does not grow, or the lowest stage of its being is no explanation of its true nature."

In this way may a perfect loyalty to the evolution doctrine throughout the entire domain of cosmic process, from its lowest to its highest manifestations, bring with it an emancipation from bondage to those mechanical principles which seem alone suggested on the lower plane of the inorganic and which may, for certain purposes, though with more conscious effort, be applied throughout the whole sphere of objective science. 
On the motion of Mr. Henry Deane, M.A., a most cordial vote of thanks was accorded to the President for his interesting Address.

The Hon. Treasurer read his final report on the Society's financial condition and outlook, and presented his accounts and balance sheet, duly signed by the Auditors as correct. From these it appeared that the balance standing at the credit of the Society on both Income and Bacteriology accounts was $£ 60714 \mathrm{~s}$. $2 d$, but that when the Society's income account only was considered, there was a small excess of expenditure over income for the year amounting to $£ 63 \mathrm{~s} .11 \mathrm{~d}$.

On the motion of Rev. J. M. Curran, seconded by Mr. W. W. Froggatt, the Hon. Treasurer's report was adopted.

On the motion of Mr. J. R. Garland, seconded by Mr. W. S. Dun, a resolution expressive of the Society's regret at Dr. Norton's retirement from the office of Hon. Treasurer, and of its weighty obligations to him for his valuable services during a period of sixteen years, was carried with acclamation.

The following gentlemen were elected to fill eight vacancies in the Council :-Professor J. T. Wilson, M.B., Ch.M. (President), J. C. Cox, M.D., F.L.S., Thomas Dixson, M.B., Ch.M., Prof. W. A. Haswell, M.A., D.Sc., F.R.S., Hon. James Norton, LL.D., M.L.C., Perceval R. Pedley, Prosper N. Trebeck, J.P., Walter W. Froggatt, F.L.S.

And as Auditons : Hugh Dixson, J.P., Edward G. W. Palmer, J.P. 


\section{$2 \mathrm{BHL}$ Biodiversity Heritage Library}

Wilson, J T. 1898. "Presidential Address." Proceedings of the Linnean Society of New South Wales 22, 812-847. https://doi.org/10.5962/bhl.part.12748.

View This Item Online: https://www.biodiversitylibrary.org/item/22896

DOI: https://doi.org/10.5962/bhl.part.12748

Permalink: $\underline{\text { https://www.biodiversitylibrary.org/partpdf/12748 }}$

\section{Holding Institution}

MBLWHOI Library

\section{Sponsored by}

MBLWHOI Library

\section{Copyright \& Reuse}

Copyright Status: NOT_IN_COPYRIGHT

This document was created from content at the Biodiversity Heritage Library, the world's largest open access digital library for biodiversity literature and archives. Visit BHL at https://www.biodiversitylibrary.org. 